\title{
INTERSTITIAL DELETION OF THE SHORT ARM OF CHROMOSOME 10: REPORT OF A CASE AND REVIEW OF THE LITERATURE
}

\author{
Zenichiro Kato,* Tomomi Kato, Naomi Kondo, \\ and Tadao OrII \\ Department of Pediatrics, Gifu University School of Medicine, \\ 40 Tsukasa, Gifu 500, Japan
}

\begin{abstract}
Summary The fifth patient with an interstitial deletion of the short arm of chromosome 10 is described. She showed most of the features observed in other known patients at age 20, including psychomotor retardation, distinct facial dysmorphism, abnormally shaped skull and cardiac malformation, while she did not show any growth retardation. The elevation of serum IgG level was observed from age 15, but she did not show DiGeorge syndrome. These differences would be explained by the differences in the amount of deleted segments using high resolution chromosome banding and molecular methods.

Key Words chromosome 10, short arm deletion, growth retardation, hypergammaglobulinemia, valproic acid
\end{abstract}

\section{INTRODUCTION}

Since the original observation by Elliot et al. (1970), about 20 patients with de novo partial deletion of chromosome $10 \mathrm{p}$ have been described. To date, there have been at least four patients reported to show an interstitial deletion of $10 \mathrm{p}$ (Juberg et al., 1981; Danesino et al., 1984; Obregon et al., 1992). We report an additional case with an interstitial deletion of the short arm of chromosome 10.

\section{CASE REPORT}

The patient, a 20-year-old female, is the second child of healthy unrelated parents. The father and mother of the child at the time of birth were 29 and 25

Received February 21, 1996; Revised version accepted July 8, 1996.

* To whom correspondence should be addressed. 
years old respectively. She was born at 42 weeks of uncomplicated gestation and her birth weight was $3,200 \mathrm{~g}$. Family history was unremarkable. Her psychomotor development was retarded. It took 5 months for the acquisition of head control, 1 year and 8 months for walking alone. At age 7, a heart murmur was noticed and she was diagnosed as having an atrial septal defect for which she underwent surgery. At age 15, she had tonic convulsions and electroencephalogram (EEG) showed diffuse spike-waves at intermittent photo-stimulation. After valproic acid was started based on a diagnosis of epilepsy, convulsions were controlled and EEG findings normalized.

The major clinical features at age 20 included mild psychomotor retardation without growth retardation (height $157 \mathrm{~cm}$, body weight $61 \mathrm{~kg}$ at age 20), downslanted palpebral fissures, ptosis, epichanthus, depressed nasal bridge, anteverted nostrils, micrognathia and small dysplastic ears. A CT scan of the head showed diffuse cortical atrophy and ventricular dilatation. Urinalysis and renal ultrasound revealed no abnormality. Laboratory investigations were grossly normal, including serum calcium concentration, parathyroid hormone level, $\operatorname{IgA}, \operatorname{IgM}, \operatorname{IgG} 2$, IgG3, IgG4 and lymphocyte responses to phytohemagglutinin and concanavalinA, while elevation of serum IgG and IgGl levels persisted from age 15 (IgG 2,467 $\mathrm{mg} / \mathrm{dl}$, IgG1 1,360 $\mathrm{mg} / \mathrm{dl}$ at age 20 ).

\section{CYTOGENETIC STUDY}

Chromosome analysis of peripheral blood cells using G-banding showed an interstitial deletion of $10 \mathrm{p} 11$ to pl3. The karyotype was $46, \mathrm{XX}$, del(10)(pl1pl3). We could not detect more precise breakpoints with high resolution G-banding technique (Ikeuchi, 1984). The deletion seemed to be $10 \mathrm{p} 11.21$ to pl2.32 or 10 p11.23 to p13 (Fig. 1). Her parents' karyotypes were normal.

\section{DISCUSSION}

We are aware of 22 patients with a partial deletion of the short arm of chromosome 10 (Elliot et al., 1970; Juberg et al., 1981; Oka et al., 1983; Danesino et al., 1984; Elstner et al., 1984; Koenig et al., 1985; Greenberg et al., 1986; Monaco et al., 1991; Kinoshita et al., 1992; Obregon et al., 1992; Shapira et al., 1994). In 21 patients the imbalance was de novo: terminal deletion was found in 17 patients and interstitial deletion in four. One patient was derived from maternal reciprocal translocation (Genick et al., 1983).

Table 1 shows a review of the clinical features of the patients with an interstitial deletion of $10 \mathrm{p}$, including the present case, and a comparison with those of patients with $10 \mathrm{p}$ terminal deletion at the breakpoint $\mathrm{pl} 3$ or $\mathrm{p} 14$. In all the $10 \mathrm{p}-$ cases, the skull shape was always abnormal with a prominent forehead. More than half of the patients had specific ocular anomalies, including downslanted palpe- 


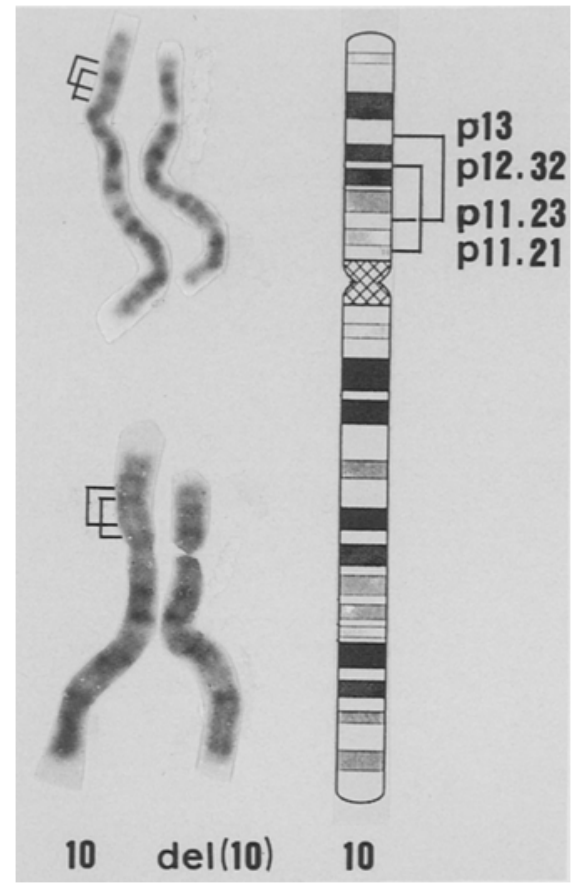

Fig. 1. Partial karyotype with GTG banding. The deleted chromosome 10 is on the right. Idiograms of normal and possible deletion patterns are shown.

bral fissures, epicanthal folds, hypertelorism and ptosis. In general, the nasal bridge was low and nostrils anteverted. Micrognathia and dysplastic ears were common features. Extremities showed heterogeneous abnormalities, including syndactyly, preaxial polydactyly, club hand and feet, clinodactyly, broad or proximally implanted thumbs, and hypoplastic distal phalanges. Half of the patients had congenital heart disease which was the major cause of death within the first months of life. Urinary tract anomalies were found in more than one third of the patients, which showed either aplastic, hypoplastic or dysplastic kidneys, hydronephrosis, duplicated ureters and urethral stenosis. Dilatation of cerebral ventricles and hypoplasia of brainstem, cerebellum or olfactory bulbs were documented in some patients. These pathological findings could be the cause of psychomotor delay and hearing disability, while there have not been reported the symptoms such as cerebeller ataxia or smelling disorder.

Elstner et al. (1984) suggested that monosomy of chromosomal material in $10 \mathrm{p} 13$ band might be what was necessary to produce the recognizable craniofacial features. We could not find clear-cut distinguishable features between interstitial deletion and terminal deletion from p13, both of which had a deletion of p13. However, terminal deletion from p14, which did not have a deletion of p13 by Gbanding technique, also showed no clear-cut distinguishable feature from the 


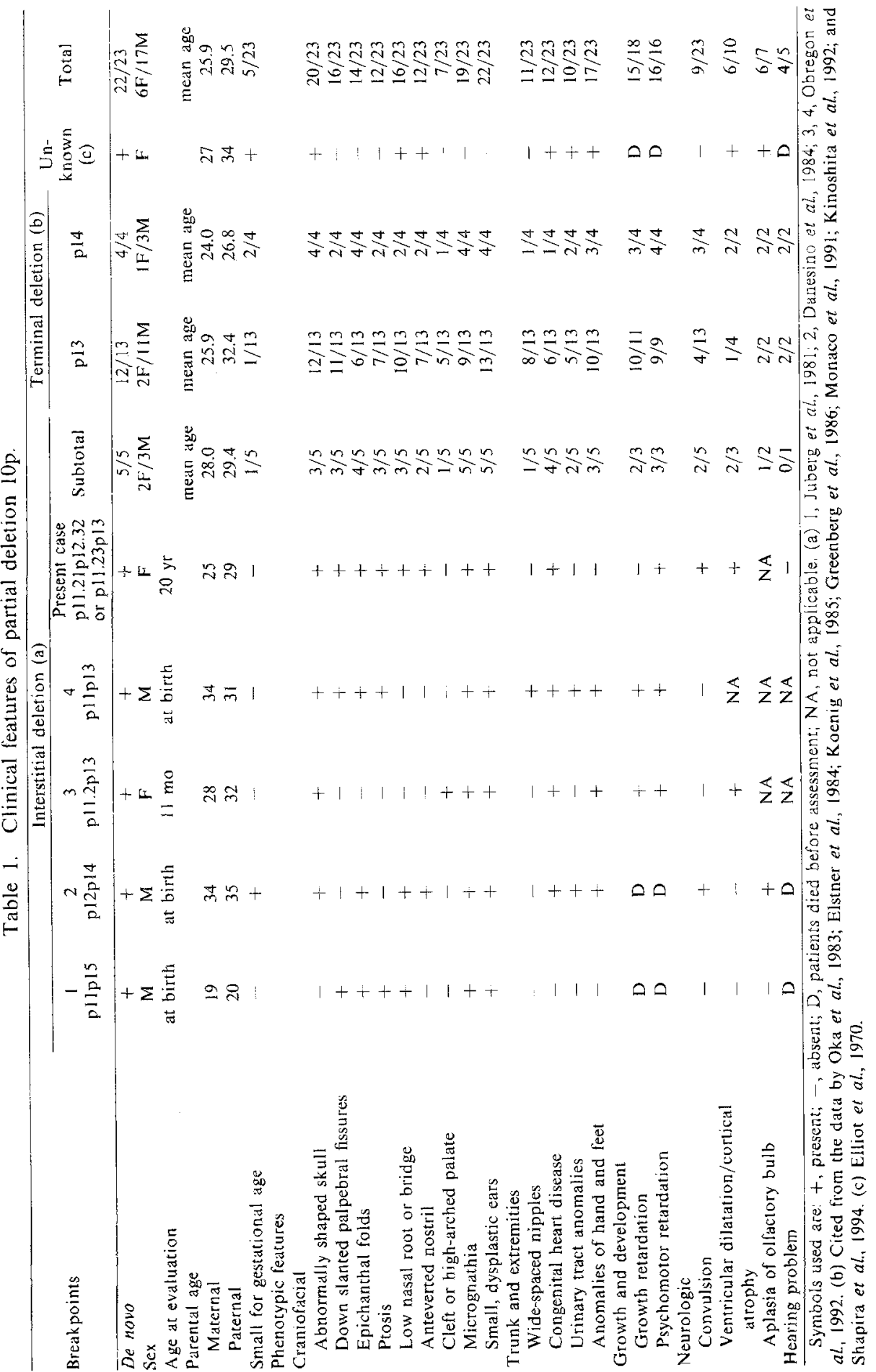


others (Table 1). Our patient did not show any growth retardation but only manifested mild psychomotor retardation, while most patients had both kinds of retardations. Although the responsible region is unclear, its effect might work mainly on growth after birth, because only a few cases have intrauterine growth retardation. To clarify the genotype-phenotype correlation of the $10 \mathrm{p}$-cases, it is necessary to perform more precise cytogenetical and molecular analyses at varied segments on the newly diagnosed cases and also on the reported cases.

Some patients with deletion of $10 \mathrm{p}$ had evidence of partial DiGeorge syndrome (DGS) (Koenig et al., 1985; Monaco et al., 1991; Obregon et al., 1992). DGS is a heterogeneous entity in which thymic and parathyroid aplasia or hypoplasia, cardiac malformations, and dysmorphic features are manifested in different combinations and expressivity. Our patient had dysmorphic features and congenital heart disease, but she did not have hypocalcemia and the characteristic immunological abnormalities.

The elevation of the serum IgG level in our patient has been observed from age 15, at the age when valproic acid therapy was started. The relation between antiepileptic drugs and serum immunoglobulin levels has been reported (Lenti et $a l ., 1991$ ), but the relation between hypergammaglobulinemia and valproic acid is unclear. In future, careful observation of the immunoglobulin levels after cessation of valproic acid treatment should be undertaken. This is important in order to establish whether the hypergammaglobulinemia is either a side effect of valproic acid or a genetic effect.

Acknowledgments We wish to thank Prof. Tadashi Kajii, Keiko Takahashi and Takazumi Kozaki of SRL, Inc. for their kind advice and manuscript preparation.

\section{REFERENCES}

Danesino C, Lo Curto F, Bonfant G, Cazzadore C, Voltolin G, Bersi S (1984): Deficiency 10p. Report of a case and exclusion mapping of the hexokinase 1 locus to band 10p11.2. Ann Génét 27: 162-166

Elliot D, Thomas GH, Condon CJ, Khuri N, Richardson F (1970): C-group chromosome abnormality (?10p-). Am J Dis Child 110: 72-73

Elstner CL, Carey JC, Livingston G, Moeschler J, Lubinsky M (1984): Further delineation of the 10p deletion syndrome. Pediatrics 73: 670-675

Genick A, Brönniman U, Tobler R, auf der Maur P (1983): Partial monosomy of chromosome 10 short arms. J Med Genet 20: 107-111

Greenberg F, Valdes C, Rosenblatt HM, Kirkland JL, Ledbetter DH (1986): Hypoparathyroidism and $T$ cell immune defect in a patient with 10p deletion syndrome. J Pediatr 109: 489-492

Ikeuchi T (1984): Inhibitory effect of ethidium bromide on mitotic chromosome condensation and its application to high-resolution chromosome banding. Cytogenet Cell Genet 38: 56-61

Juberg RC, Stallard R, Straughen WJ, Avotri KJ, Washington JW (1981): Clinicopathological conference: a newborn monozygotic twin with abnormal facial appearance and respiratory insufficiency. Am J Med Genet 10: 193-200

Kinoshita Y, Tanaka Y, Yasuhara A, Matsuzaki S, Kuriki H, Kobayashi Y (1992): A case of deletion of the short arm of chromosome 10 with severe hearing loss and brainstem dysfunction. Am J Perinatol 9: 299-301

Vol. 41, No. 3, 1996 
Koenig R, Kessel E, Schoenberger W (1985): Partial monosomy I0p syndrome. Ann Génét 28: $173-176$

Lenti C, Masserini C, Peruzzi C, Guareschi-Cazzulo A (1991): Effects of carbamazepine and valproate on immunological assessment in young epileptic patients. Ital J Neurol Sci 12: 8791

Monaco G, Pignata C, Rossi E, Mascellaro O, Cocozza S, Ciccimarra F (1991): DiGeorge anomaly associated with $10 \mathrm{p}$ deletion syndrome. Am J Med Genet 39: 215-216

Obregon MG, Mingarelli R, Gianotti A, di Comite A, Spedicato FS, Dallapiccola B (1992): Partial deletion 10p syndrome. Report of two patients. Ann Génét 35: 101-104

Oka S, Nakano H, Yokochi T, Ueda K, Saito A (1983): Distal deletion of the short arm of chromosome No. 10: A case report. Jpn J Human Genet 28: 291-296

Shapira M, Borochowitz Z, Bar-El H, Dar H, Etzioni A, Lorber A (1994): Deletion of the short arm of chromosome 10 (10p13): Report of a patient and review. Am J Med Genet 52: 34-38 